\title{
La posible aplicación del principio sic utere tuo ut alienum non laedas para abordar el daño ambiental transfronterizo en el ordenamiento jurídico hondureño
}

\author{
Claudia María Castro Valle*
}

\begin{abstract}
RESUMEN
Con este trabajo se busca exponer las formas en que el sistema de fuentes del ordenamiento jurídico hondureño adopta el principio sic utere tuo ut alienum non laedas, y su posible implementación como solución al daño ambiental transfronterizo. Implementación que puede darse ya sea por medio de las normas convencionales, por medio de la costumbre internacional o por la vía jurisprudencial. Con el propósito de entender dichas posibilidades y poder aprovecharlas, se hace un breve análisis de los casos concretos en los que dicho principio ha sido aplicado en el ámbito internacional, a modo que sirva de base comparativa con el que se contrasta el caso hondureño.
\end{abstract}

Daños - responsabilidad ambiental - contaminación transfronteriza

\section{The posible application of the principle sic utere tuo ut alienum non laedas to address cross-border environmental tort in the bonduran legal system}

\begin{abstract}
This paper seeks to expose the ways in which the sources of the Honduran legal system adopt the principle sic utere tuo ut alienum non laedas, and its possible implementation as a solution for transboundary environmental tort. The implementation of such principle could happen either by means of conventional norms, of international customary law, or via legal jurisprudence. In order to understand the available opportunities and the possibility of taking advantage of them, a brief analysis of the specific cases in which this principle has been applied at the international level is made, to serve as a comparative basis with which the Honduran case is contrasted.
\end{abstract}

Damages - environmental Liability - transfrontier pollution

*Abogada. Doctora en Estudios Jurídicos, Ciencia Política y Criminología, Universidad de Valencia, España. Profesora de Derecho, Facultad de Postgrado de la Universidad Tecnológica Centroamericana (UNITEC), Honduras. Correo electrónico: claudia.castro@unitec.edu.hn.

Artículo recibido el 28 de septiembre de 2017 y aceptado para su publicación en este número el 18 de enero de 2019. 


\section{INTRODUCCIÓN}

$\mathrm{E}$ 1 Estado de Honduras, al formar parte del Sistema de Integración Centroamericano (SICA) y de la Unión Aduanera con Guatemala, pasa por un momento en el que sus autoridades gubernativas apuestan precisamente a fomentar la inversión extranjera para que, entre otras cosas, impulse el crecimiento de la industria local. Situación que es muy similar a la de sus vecinos. Lo anterior puede suponer que el riesgo de ocurrencia de daño ambiental transfronterizo se vea potenciado. De ahí que sea relevante entender si el Estado de Honduras, así como se prepara para atraer y fomentar la inversión y la industria, también está tomando las medidas necesarias para enfrentar los efectos negativos que este tipo de actividades económicas pueden traer consigo. Medidas que, indiscutiblemente, deben tener la forma de soluciones jurídicas.

Este trabajo busca demostrar la relevancia que tiene el principio sic utere tuo ut alienum non laedas ${ }^{1}$, para enfrentar estos conflictos, así como analizar su posible aplicación, en el supuesto específico del daño ambiental transfronterizo y valorar si con ello se cuenta con instrumentos adecuados para abordar el problema de la responsabilidad ambiental internacional desde el ordenamiento jurídico hondureño. Un principio jurídico que, además, ha sido adoptado por el Derecho Internacional Público. Con ello se trata de determinar si es posible aceptar las hipótesis de investigación utilizadas.

La primera de estas hipótesis señala que no es parte de la política exterior del Estado de Honduras la ratificación de instrumentos internacionales que contengan dicho principio, y con ello asegurar la adecuada deducción de la responsabilidad ambiental internacional en supuestos de daño ambiental transfronterizo causado en el territorio nacional. La segunda hipótesis de trabajo establece que no es parte de la política legislativa del Estado de Honduras fortalecer el sistema de fuentes del Derecho Internacional Privado para asegurar la adecuada deducción de la responsabilidad civil por daño ambiental transfronterizo, cuando sea causado por particulares hondureños, o cuando sean ciudadanos hondureños los que resulten afectados en su persona o en su patrimonio.

\section{EL RECONOCIMIENTO DEL PRINCIPIO SIC UTERE TUO UT ALIENUM NON LAEDAS en el Derecho Internacional Público}

El principio sic utere tuo ut alienum non laedas nace en el Derecho romano, basado en la noción de la equidad. No obstante, en el Derecho Internacional, la aplicación de este principio tiene un origen más bien consuetudinario. Con su aplicación, los miembros de la sociedad internacional se comprometen a usar su territorio de maneras que no sean dañosas para los demás Estados ${ }^{2}$. Su periplo por el Derecho Internacional Público se

\footnotetext{
${ }^{1}$ La máxima se traduce al castellano como "usa tu propiedad, pero sin dañar la del otro".

${ }^{2}$ Drnas, 2012, p. 9.
} 
inicia en el texto de la Declaración de la Conferencia de las Naciones Unidas sobre el Medio Ambiente Humano, celebrada en Estocolmo, Suecia, en $1972^{3}$.

Establece el Principio 21 de dicha Declaración que los Estados tienen el derecho soberano de explotar sus propios recursos en aplicación de su propia política ambiental, pero, además, tienen la obligación de asegurar que las actividades que se lleven a cabo dentro de su jurisdicción o bajo su control no perjudiquen al medio de otros Estados o de zonas situadas fuera de toda jurisdicción nacional. Complementariamente a esto, el Principio 22 de esta Declaración también señala que los Estados deben cooperar para continuar desarrollando en el Derecho Internacional la adecuada regulación de lo referido a la responsabilidad e indemnización de las víctimas de la contaminación, así como en otros supuestos de daño ambiental que sean causados por actividades realizadas dentro de la jurisdicción o bajo el control de tales Estados, a zonas situadas fuera de su jurisdicción.

Los principios antes citados fueron retomados en la Declaración de Río sobre el Medioambiente y el Desarrollo ${ }^{4}$, celebrada en 1992 (Principios 2 y 13), agregando a las ideas heredadas de Estocolmo la noción de que los Estados deberán desarrollar la legislación nacional relativa a la responsabilidad y la indemnización respecto de las víctimas de la contaminación y otros daños ambientales. Sin embargo, a pesar de lo ostentoso que pueden sonar estas declaraciones, no se puede olvidar que al final son eso, declaraciones de Soft-law o Derecho blando, sin efecto vinculante alguno, pero que sirven para crear una base filosófica que puede ser posteriormente incorporada en tratados internacionales, o en legislación interna de los miembros de la sociedad internacional.

Habiendo establecido lo anterior, es necesario señalar cuál es la ventaja de la incorporación de este principio en instrumentos internacionales. Su aplicación busca resolver la aparente contradicción jurídica que hay cuando se habla de daño ambiental transfronterizo. Por un lado, el principio sic utere tuo ut alienum non laedas reconoce la existencia de esas barreras inmateriales denominadas "fronteras", que sirven de base para demarcar geográficamente la soberanía estatal. Una manifestación de la soberanía que se puede definir como el cúmulo de las competencias propias del Estado, que -ademásson de carácter puramente territorial.

Agregado a esto, la plenitud es una de las características de la soberanía territorial, sin que pueda presumirse ningún tipo de limitaciones respecto de ella. Esta soberanía también es exclusiva, pues no permite el ejercicio de dichas competencias territoriales por otro Estado. Adicionalmente, la soberanía territorial es inviolable, pues el Derecho Internacional faculta a los Estados la obligación de respeto a la soberanía e integridad territorial de otros Estados 5 . Por el otro lado, a pesar del efecto antes descrito, no se puede pasar por alto que el principio sic utere tuo ut alienum non laedas reconoce como hecho indiscutible que el ambiente -más allá de divisiones geográficas de factura humana- es un sistema, cuyos elementos se encuentran indefectiblemente interrelacionados.

\footnotetext{
${ }^{3}$ Declaración sobre Medio Ambiente Humano y Desarrollo, 1972.

${ }^{4}$ Declaración sobre el Medio Ambiente Humano y el Desarrollo, 1992.

${ }^{5}$ PAstor, 2015, pp. 347-349.
} 
A partir de la incorporación de este principio en el Derecho blando, el sic utere tuo ut alienum non laedas también ha sido reconocido jurisprudencialmente. Ha sido utilizado en diversas resoluciones arbitrales y judiciales de conflictos internacionales como en el caso de la Isla de Palmas, entre los Países Bajos y Estados Unidos de Norteamérica en 19286; el caso de la Fundidora Trail entre Estados Unidos de Norteamérica y Canadá en 19417 ; el caso del Canal de Corfú entre el Reino Unido y Albania en 1949 ${ }^{8}$; en el caso del Lago Lannoux entre Francia y España en 19579; en el caso concerniente al proyecto Gabčikovo-Nagymaros entre Hungría y Eslovaquia en $1999^{10}$; y, el caso sobre la planta de celulosa sobre el Río Uruguay ${ }^{11}$ entre Argentina y Uruguay en $2010^{12}$.

El reconocimiento por la vía jurisprudencial ha hecho que este principio sea asumido como una forma de cortesía entre los Estados. Una cortesía que va de la mano con la tendencia preponderante de las relaciones internacionales: la cooperación internacional $^{13}$. No obstante, desde la perspectiva ambiental, sería ideal que no quedara relegada al Derecho blando, sino que se consolidara como una verdadera obligación interestatal. El no potenciarlo por medio del Derecho Internacional Público puede tener como efecto el presentar un escenario donde prime la ausencia de regulación, o de inadecuación de esta, causando que los problemas que plagan a las litigaciones por daño ambiental transfronterizo persistan.

En este sentido, el Derecho Internacional Público no ha defraudado, habiendo asumido el reto, regulando las relaciones de vecindad que deben prevalecer entre los Estados por medio de la codificación de este principio. Además, esta disciplina ofrece otra ventaja, al permitir que este principio de informe de otros principios relevantes para el Derecho Ambiental, así como el de prevención y precaución ${ }^{14}$. Lo anterior puede percibirse, sobre todo, por medio de los esquemas previstos en algunos instrumentos internacionales que incardinan prohibiciones de causar daño en el territorio de otros Estados. El efecto de lo anterior es que la responsabilidad del Estado por daños transfronterizos puede originarse a pesar de que las lesiones que originan daños que trascienden las fronteras de dicho Estado provengan de actividades riesgosas pero lícitas.

A pesar de esto, autores como Gomis Catalá consideran que estos mecanismos son escasamente prácticos ${ }^{15}$. Independientemente de la suspicacia manifestada por un sector de la doctrina, que parece ser causada por la aparente falta de resultados, hay que reconocer

6 Tribunal Permanente de Arbitraje, 4 de abril de 1928.

7 Tribunal Permanente de Arbitraje, 16 de abril de 1938 y 11 de marzo de 1941.

${ }^{8}$ Corte Internacional de Justicia, 9 de abril de 1949.

9 Tribunal Permanente de Arbitraje, 16 de noviembre de 1957.

${ }^{10}$ Corte Internacional de Justicia, 25 de septiembre de 1997.

${ }^{11}$ Corte Internacional de Justicia, 20 de abril de 2010.

12 Elorrio, 2011, p. 9.

13 García, 2006, p. 467.

${ }^{14}$ El principio de precaución se encuentra contenido en el principio 15 de la Declaración de Río sobre Medioambiente y Desarrollo de 1992; mientras que, el principio de prevención se desprende de los Principios 2, 4 y 7 de la Declaración de Estocolmo sobre el Medioambiente Humano, de 1972.

15 Gomis, 1998, p. 25. 
que el Derecho Internacional Público no se ha detenido, y en ese trayecto ha ido incorporando instrumentos que tratan de regular la responsabilidad civil de los Estados por daño ambiental transfronterizo ${ }^{16}$, así como la responsabilidad civil y la compensación por daños a personas, bienes y al ambiente por la realización de actividades potencialmente peligrosas $^{17}$. El ejemplo más distintivo de esta tendencia es el Convenio del Consejo de Europa sobre la responsabilidad civil por los daños derivados de actividades peligrosas para el medio ambiente de $1993^{18}$, comúnmente conocido como Convenio de Lugano.

A pesar de esto, y entendiendo que hay más de una docena de tratados internacionales acerca de responsabilidad civil que regulan el daño ambiental transfronterizo que han sido negociados en esquemas multilaterales, tampoco se puede dejar de reconocer que la gran mayoría de estos instrumentos no han sido aún ratificados ${ }^{19}$. La falta de compromiso de los Estados Contratantes abona a favor de las posiciones doctrinales más escépticas.

Aún y con esta tibia recepción, la inclusión lenta pero segura del principio sic utere tuo ut alienum non laedas permite que este vaya consolidando su imperatividad, obligando de a poco a los Estados que sí reconocen la importancia de obligarse por medio de este tipo de instrumentos, a asumir un abordaje preventivo con relación al daño ambiental, particularmente en aquellos supuestos donde los efectos dañosos pueden manifestarse más allá de sus propias fronteras.

\section{LA IDONEIDAD DEL PRINCIPIO SIC UTERE TUO UT ALIENUM NON LAEDAS COMO SOLUCIÓN PARA EL DAÑO AMBIENTAL TRANSFRONTERIZO}

Si bien es cierto que al aplicar este principio se está haciendo referencia directa a la responsabilidad ambiental internacional, para Ortiz Ahlf hay que distinguir la existencia de una responsabilidad internacional que se origina a partir de los perjuicios causados por actos no prohibidos, y otra, que surge por la comisión de un ilícito internacional ${ }^{20}$. La primera, de acuerdo con García Castrejón, se determina cuando es posible imputar al menos a un Estado la realización de actividades no prohibidas que hayan causado daños y perjuicios en el territorio de otro Estado. Para el autor, esta responsabilidad será siempre objetiva, independientemente de que dicho Estado haya tomado las medidas adecuadas para evitar su causación, o de que no haya cometido infracción alguna contra normas de carácter internacional. Ambas formas de responsabilidad atañen exclusivamente al Estado, ya sea por acto u omisión que le sea imputable, o por la violación de alguna obligación de Derecho Internacional. La responsabilidad causada, además, se deduce en

\footnotetext{
${ }^{16}$ GARCÍA, 2006, p. 470.

${ }^{17}$ Kreuzer, 1992, p. 69.

${ }^{18}$ Convenio del Consejo de Europa sobre la responsabilidad civil por los daños derivados de actividades peligrosas para el medio ambiente, 1993.

${ }^{19}$ Percival, 2010, pp. 2-3.

${ }^{20}$ GARCía, 2006, pp. 473-474.
} 
el plano diplomático-judicial. Es decir, el reclamo que se suscite por causa de una lesión al ambiente provendrá siempre de otro Estado, el que considera haber sufrido un daño ${ }^{21}$.

Es obvio, entonces, que si bien es cierto la opción ofrecida por el Derecho Internacional Público es necesaria, la aplicación del principio sic utere tuo ut alienum non laedas por esa vía puede peligrar, al depender de los intereses de la política exterior de los Estados, que no necesariamente habrán de coincidir con el genuino interés de tutelar al ambiente. Adicionalmente, esa misma dependencia de la política exterior que es implementada por cada Estado, puede tener como efecto que las reclamaciones por daño ambiental transfronterizo sean relativamente escasas ${ }^{22}$.

Este extremo también ha sido recogido por la literatura especializada, la que no escatima en señalar que, a pesar de la existencia de estos instrumentos internacionales, los Estados se muestran reacios a admitir su responsabilidad cuando la naturaleza de los daños es ambiental, aunque esta responsabilidad sea un principio reconocido del Derecho Internacional. Y con razón, pues además de ser aún pocos los tratados internacionales existentes en los que se reconoce la responsabilidad internacional estatal, normalmente estos se limitan a los supuestos de daños nucleares y contaminación por hidrocarburos, lo que puede deberse a la magnitud del riesgo y de los perjuicios, los que son mucho más elevados que lo normal.

La evidente displicencia de los miembros de la Sociedad Internacional a dar el siguiente paso, hace que sea necesario trasladar el conflicto al ámbito del Derecho Privado. Esto permite que la responsabilidad en lugar de ser deducida al Estado en cuyo territorio se lleva a cabo la acción dañosa, sea descontada directamente al contaminador que la genera ${ }^{23}$. De ahí que, ante la renuencia de los Estados de asumir directamente la responsabilidad que les corresponde devenida de su deber de vigilancia, estos hayan pretendido ir creando instrumentos multilaterales que contienen normas que establecen el Derecho sustantivo que ha de aplicarse ${ }^{24}$ en estos conflictos internacionales de orden privado $^{25}$. Y, de hecho, puede ser que, en realidad, este sea el camino más adecuado.

A tal efecto, debe señalarse que la excepcionalidad de los instrumentos convencionales que contienen normas sustantivas internacionales reside en la necesidad de lograr un equilibrio entre los intereses económicos de la industria a no asumir la totalidad de los riesgos, y el interés de las víctimas a ser reparadas íntegramente ${ }^{26}$. Estos tratados normalmente tienen dos objetivos: eliminar los obstáculos que pueden presentarse si se intentaran resolver utilizando las normas de conflicto propias de los sistemas estatales internos de Derecho Internacional Privado, así como garantizar el resarcimiento del daño para compensar efectivamente a la víctima ${ }^{27}$.

\footnotetext{
${ }^{21}$ Ortiz, 1999, pp. 383-386.

22 Percival, 2010 , p. 5.

${ }^{23}$ Martín, 2000, p. 331.

24 NAFZiger, 2002, p. 342.

${ }^{25}$ PalaO, 2016, p. 654.

26 Bouza, 1984, p. 74.

${ }^{27}$ Zilioli, 1995, p. 197.
} 
Este particular tipo de tratados internacionales abarca normalmente aspectos como la definición de las actividades a las que se podrán aplicar, los lugares en las que estas podrían acontecer, las personas que podrían ser responsables, y la posible responsabilidad residual de los Estados. También es común encontrar que estos instrumentos establecen sistemas de responsabilidad objetiva de parte del operador causante del daño ${ }^{28}$. Además, tienden a favorecer que se instituyan garantías financieras para cubrir riesgos, tales como la constitución de fondos para la compensación de los daños. Para esto se esfuerzan en delimitar las categorías de daños que pueden ser resarcidos, los límites de la responsabilidad económica de los operadores, el régimen de prescripción de las reclamaciones, e incluso aborden otros problemas propios del Derecho Internacional Privado, al determinar cuáles son los tribunales con jurisdicción para conocer de estos casos, así como lo referente a la ejecución de sentencias que de ellos procedan.

\section{LA INCORPORACIÓN DEL PRINCIPIO EN EL ORDENAMIENTO JURÍDICO HONDUREÑO}

La Corte Suprema de Justicia Hondureña también ha recogido el principio sic utere tuo ut alienum non laedas en su Sentencia SJCSJ-RI0066 del 19 de octubre de $2006^{29}$, señalando que “...el Estado de Honduras tiene el derecho soberano y la obligación ineludible de beneficiar a la población presente y futura con la explotación de sus riquezas naturales y para ello debe diseñar su propia política ambiental, propiciando que bajo su control no se perjudique el medio ambiente propio y de otros Estados". No obstante, poco ha hecho para que su reconocimiento jurisprudencial se traduzca en reconocimiento normativo.

Esto es fácilmente comprobable pues el Estado de Honduras ha suscrito y ratificado poquísimos tratados internacionales concernientes a responsabilidad civil internacional. Únicamente puede mencionarse la Convención de las Naciones Unidas sobre el Derecho del Mar, suscrito el 10 de diciembre de 1982, y ratificado el 5 de octubre de $1993^{30}$. Esta herramienta se considera una solución híbrida, al pertenecer a una categoría que no solo busca establecer mecanismos que permitan deducir la responsabilidad civil por daños a los particulares, sino que permite combinar tanto la responsabilidad del individuo con la del Estado. En este caso específico se declara la responsabilidad internacional del Estado, a la vez que señala la relevancia de la responsabilidad de las personas físicas, que deberá ser regulada por el Derecho interno de los miembros ${ }^{31}$.

En 2002, el Estado de Honduras hace una declaración oficial respecto del texto de la Convención, específicamente acerca del párrafo primero del artículo 287, en el que se

\footnotetext{
${ }^{28}$ Ortiz, 1999, pp. 383-386.

${ }^{29}$ Corte Suprema de Justicia de Honduras, 19 de octubre de 2006, No SJCSJ-RI0066.

${ }^{30}$ Convención de las Naciones Unidas sobre el Derecho del Mar, 1982.

31 Gomis, 1998, p. 36.
} 
establece que se escoge la Corte Internacional de Justicia como el medio para la solución de conflictos que devengan de la interpretación o aplicación de dicha Convención, aunque se reserva la posibilidad de considerar otros medios de resolución pacífica de conflictos, como el Tribunal Internacional de los Derechos del Mar, decisión que se tomará tras el análisis de cada caso concreto ${ }^{32}$.

El Estado de Honduras tampoco ha sido muy proclive a suscribir tratados internacionales que contengan soluciones de Derecho Internacional Privado que venga a resolver el conflicto de leyes o el conflicto de jurisdicciones, y que permitan que sean los particulares los que reclamen la reparación de los daños por ellos sufridos como consecuencia de la contaminación ambiental transfronteriza. A pesar de que estos tratados no siempre logran resolver el problema de la competencia judicial internacional, pues raras veces incluyen reglas claras para la escogencia de los foros. Su verdadera utilidad radica en resolver el conflicto de leyes para los supuestos específicos que abordan.

Por un lado, en lo que al daño nuclear corresponde, Honduras no ha ratificado la Convención sobre Responsabilidad de Terceros en el Sector de la Energía Nuclear ${ }^{33}$, también conocida como Convención de París de 1960, ni su protocolo adicional de $1964^{34}$. Tampoco han sido ratificados por Honduras la Convención de Bruselas sobre la responsabilidad de los explotadores de buques nucleares de $1962^{35}$, la Convención de Viena sobre responsabilidad civil por daños nucleares de $1963^{36}$, ni el Convenio de Bruselas relativo a la responsabilidad civil en la esfera del transporte marítimo de sustancias nucleares de $1971^{37}$.

No obstante, por el otro lado, en lo que a la contaminación por hidrocarburos se refiere, Honduras sí ha suscrito y ratificado la Convención Internacional sobre Responsabilidad Civil por Daños debidos a la Contaminación por Hidrocarburos (CLC) de $1969^{38}$; aunque no así en lo referente a los posteriores protocolos a este tratado, que datan de 1992. Agregado a lo anterior, Honduras tampoco ratificó el Convenio Internacional de Indemnización de Daños causados por la Contaminación de Hidrocarburos ${ }^{39}$ o Convenio del Fondo de $1971^{40}$.

32 Organización de las Naciones Unidas, 2017.

33 Convención sobre Responsabilidad de Terceros en el Sector de la Energía Nuclear, 1960.

${ }^{34}$ Protocolo Adicional a la Convención sobre Responsabilidad de Terceros en el Sector de la Energía Nuclear, 1964.

${ }^{35}$ Convención sobre la responsabilidad de los explotadores de buques nucleares, 1962.

36 Convención sobre responsabilidad civil por daños nucleares, 1963.

37 Convenio relativo a la responsabilidad civil en la esfera del transporte marítimo de sustancias nucleares, 1971.

38 Convención Internacional sobre Responsabilidad Civil por Daños debidos a la Contaminación por Hidrocarburos, 1969.

${ }^{39}$ Convenio Internacional de Indemnización de Daños causados por la Contaminación de Hidrocarburos, 1971.

${ }^{40}$ El Convenio del Fondo dejó de estar vigente en el 2002 cuando el número de Estados miembros se redujo por debajo de 25 . 


\section{UNA POSIBLE ALTERNATIVA}

Una forma indirecta de llenar este vacío que se ha identificado, sería asegurar que el sistema de fuentes del Derecho Internacional Privado incluya soluciones que permitan deducir responsabilidad por daños a los particulares. Si bien con esto no se resolvería directamente el problema de la responsabilidad ambiental internacional, podría ser una vía alternativa para lograr el fin ulterior de este principio, que es la protección ambiental del ambiente. Visto desde esa perspectiva, hay que señalar que el sistema hondureño de fuentes de Derecho Internacional Privado también contiene poquísimas soluciones, y se caracteriza por la escasa elaboración legislativa y su carácter rígido e inflexible ${ }^{41}$. Agregado a esto, Honduras tampoco ha ratificado ningún tratado internacional genérico sobre la determinación de competencia judicial o para resolver el conflicto de leyes en supuestos de responsabilidad civil por daños, salvo la Convención Interamericana sobre Normas Generales de Derecho Internacional Privado ${ }^{42}$, que suscribió, pero no ha ratificado. La única fuente convencional disponible y vigente en la materia es el Código de Bustamante ${ }^{43}$, que data de 1928.

De ahí que se siga enfatizando la importancia que tiene el que el Estado de Honduras ratifique o se adhiera a los pocos tratados disponibles en este ámbito, pues no se puede negar que estos instrumentos están dotados de cierta utilidad y de alguna efectividad, siempre y cuando -claro está- sea amplio el número de los Estados que los ratifiquen o se adhieran a ellos. Efectividad que -además- podría verse mejorada dependiendo solo si el esquema de reparación que contiene es adecuado para la víctima ${ }^{44}$. Sin embargo, también hay que tener claridad con relación a las limitantes de estos instrumentos, pues, como señala Percival, la efectividad de estos tratados se ve seriamente disminuida por las dificultades existentes para satisfacer los requerimientos de la individualización de la prueba requerida para demostrar la causalidad del daño ${ }^{45}$. Por tanto, también se hace necesario establecer si Honduras ha suscrito y ratificado tratados internacionales acerca de aspectos procesales que sirvieran para facilitar la aplicación de los instrumentos de convencionales de Derecho Internacional Privado antes señalados.

En el ámbito del Derecho continental americano, Honduras ha suscrito y ratificado la Convención Interamericana sobre la Recepción de Pruebas en el Extranjero en materia civil y mercantil desde $1979^{46}$. Además, ha firmado y ratificado la Convención Interamericana sobre Exhortos o Cartas Rogatorias ${ }^{47}$ también desde ese año. Asimismo, suscribió la Convención Interamericana sobre el Cumplimiento de Medidas Cautelares ${ }^{48}$

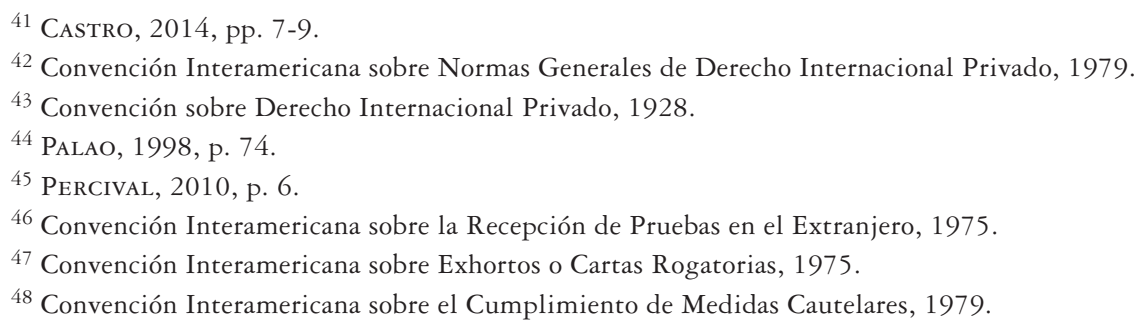


también en 1979, aunque esta última aún no la ha ratificado. Ni tampoco ha suscrito la Convención Interamericana sobre Competencia en la Esfera Internacional para la Eficacia Extraterritorial de las Sentencias Extranjeras ${ }^{49}$ que entró en vigencia el 24 de diciembre de 2004.

Esta reticencia por parte del Estado de Honduras a suscribir tratados internacionales de esta naturaleza, en definitiva, deja sin herramientas a los nacionales de este Estado para poder iniciar procesos para reclamar indemnización por daños como consecuencia de lesiones al ambiente acaecidas desde el territorio de sus Estados vecinos. Agregado a esto, pareciera que el Estado de Honduras ha querido llenar este vacío suscribiendo y ratificando convenciones que se limitan a enunciar la necesidad sistemas de responsabilidad por daño y a transferir la solución de esta necesidad a las herramientas disponibles en los ordenamientos jurídicos internos de los Estados Contratantes.

Son varios los ejemplos que se pueden citar a este respecto. Para comenzar, en 1992 los Estados centroamericanos suscriben el Acuerdo Regional sobre el Movimiento Transfronterizo de Desechos Peligrosos ${ }^{50}$. Este instrumento contiene disposiciones generales respecto del sistema de control de esta tipo de sustancias que será adoptado en la región. Tal como se adelantó, no contiene normas específicas relativas a la responsabilidad civil por daños causados por el transporte o uso de estas.

Sin embargo, esta particularidad de solo manifestar la necesidad de deducir responsabilidad civil por daño ambiental no es exclusiva de instrumentos generados en Centroamérica, también se aprecia en el ámbito extrarregional. Un ejemplo de lo anterior es el Convenio de Basilea sobre el control de los movimientos transfronterizos de los residuos peligrosos y su eliminación ${ }^{51}$. Honduras accede formalmente como Estado parte de este Convenio en 1995. Este instrumento solo obliga a las partes a cooperar con el fin de adoptar un procedimiento para delimitar la responsabilidad por daños a cargo de los contaminadores ${ }^{52}$.

En este mismo orden, el Estado de Honduras también suscribió el Convenio sobre Diversidad Biológica en $1992^{53}$ y la ratificó en 1995. El artículo 14 señala que la Conferencia de las partes examinará, a base de estudios, el tema de la responsabilidad y la reparación, incluyendo la restauración y la indemnización por daños a la diversidad biológica, salvo cuando esa responsabilidad sea una cuestión interna que puede ser resuelta por los Estados por su cuenta.

De la Convención sobre Diversidad Biológica se desprende el Protocolo de Cartagena sobre Bioseguridad ${ }^{54}$. Este fue suscrito por Honduras en el 2000, ratificado en el 2008,

${ }^{49}$ Convención Interamericana sobre Competencia en la Esfera Internacional para la Eficacia Extraterritorial de las Sentencias Extranjeras, 1984.

50 Acuerdo Regional sobre el Movimiento Transfronterizo de Desechos Peligrosos, 1992.

51 Convenio sobre el control de los movimientos transfronterizos de los residuos peligrosos y su eliminación, 1989.

52 Gomis, 1998, p. 36.

53 Convenio sobre Diversidad Biológica, 1992.

${ }^{54}$ Protocolo sobre Seguridad en la Biotecnología, 2000. 
entrando en vigencia un año después. El artículo 27 de este instrumento señala que la Conferencia de las Partes, en su primera reunión, establecerá un proceso en relación con la elaboración apropiada de normas y procedimientos internacionales en el campo de la responsabilidad y compensación por daños resultantes de movimientos transfronterizos de organismos vivos modificados, teniendo debidamente en cuenta los procesos en curso en Derecho internacional referente a esos ámbitos, y tratará de completar ese proceso dentro de cuatro años.

Con ese fin se crea dentro del contexto del Protocolo de Cartagena un Protocolo suplementario, el de Nagoya-Kuala Lumpur ${ }^{55}$. El artículo 12 de este documento se refiere a la implementación y relación de la responsabilidad civil. Este establece que los Estados parte proveerán dentro de sus ordenamientos internos reglas y procedimientos para regular el daño, sea utilizando las ya existentes o desarrollando otras creadas específicamente con este propósito. Estas normas deberían de abordar temas específicos como el concepto de daño, estándares de responsabilidad, ya sean objetivos o subjetivos, canalización de la responsabilidad y el derecho a presentar reclamos. Sin embargo, Honduras aún no ha suscrito ni ratificado este instrumento.

El reconocer la necesidad de establecer sistemas interestatales para deducir responsabilidad por daños ambientales transfronterizos, sin comprometerse, ratificando los instrumentos que van apareciendo en el ámbito internacional, y que están a disposición de los Estados, termina restándole efectividad al principio sic utere tuo ut alienum non laedas. En el caso de Honduras, sería relevante suscribir y ratificar los tratados que hacen falta, pues las fuentes internas de este ordenamiento jurídico no resuelven claramente ni el conflicto de leyes, como tampoco lo hace con el conflicto de competencia judicial.

\section{Conclusiones}

Como ha quedado evidenciado, el principio sic utere no ha logrado introducirse contundentemente como una norma efectivamente positiva del Derecho Internacional Público, al no haberse logrado codificarlo con la normalidad deseada para que los Estados puedan resarcirse unos a otros en el evento de la causación de daño ambiental transfronterizo.

Además de lo anterior, en el caso específico hondureño, ha quedado evidenciado la reticencia de las autoridades gubernativas con relación a suscribir o ratificar los pocos tratados internacionales disponibles que le permitan a Honduras reclamar la debida reparación por la causación de esos daños en Tribunales internacionales de justicia, tal vez adelantándose al hecho de que, más bien, pudiera ser el Estado de Honduras al que se le condene por esta causa.

55 Protocolo sobre responsabilidad y compensación suplementario al protocolo de Cartagena sobre seguridad de la biotecnología, 2010. 
Es así como la posibilidad de deducir efectivamente la responsabilidad por daño ambiental transfronterizo causado o sufrido en Honduras es relativamente escaso, por no decir nulo, poniendo en precario no solo el derecho de la actual generación a gozar de un ambiente sano y equilibrado, sino que también de las generaciones que están por venir. Quedando, tal vez, como última instancia el reconocimiento por la vía jurisprudencial, en el evento de que un caso concreto sea conocido por un Tribunal Internacional, en el sentido de que el principio sic utere tuo ut alienum non laedas sea reconocido por este como un principio general del Derecho, como se ha hecho en los casos citados en el desarrollo de este documento.

Con esto, es evidente que puede validarse la primer hipótesis planteada al inicio de este trabajo, pues el Estado de Honduras no ha hecho suficientes esfuerzos para asegurar un sistema de responsabilidad ambiental internacional por medio de ratificaciones del cuerpo de Tratados Internacionales que lo desarrollan, denotando con ello que no está en su agenda. Esta tibieza por parte del Estado, impide que se cree un entorno de verdadera seguridad jurídica para los particulares que también pueden resultar afectados por las lesiones transfronterizas al ambiente.

Ahora bien, ha quedado evidenciado de igual manera, que ha sido más fácil que el Estado de Honduras se arriesgue a fortalecer su sistema de fuentes de Derecho Internacional Privado, lo que permite deducir responsabilidad por daño ambiental transfronterizo a los causantes, aunque no sean estos de naturaleza estatal. Sin embargo, hay que decirlo, tampoco es que esta opción haya sido abrazada contundentemente. Por tanto, se ha validad así la segunda hipótesis propuesta en la introducción.

Dicho esto, si la falta de compromiso del Estado de Honduras con la ratificación de tratados internacionales que aseguren la adecuada implementación del principio sic utere se debe a querer evitar verse obligado a resarcir daños de este tipo, pero quiere a pesar de esto demostrar un compromiso genuino con la protección del ambiente, entonces debe apostarle a la consolidación de un sistema de fuentes de Derecho Internacional Privado. Un sistema que permita la solución judicial de los conflictos transfronterizos entre víctimas y causantes, además de abonar a la seguridad jurídica, propia de un verdadero Estado de Derecho.

\section{BIBLIOGRAFÍA}

Bouza Vidal, Nuria, 1984: "Aspectos de Derecho internacional privado en la protección del medioambiente”, en AA. VV. VIII Jornadas de la asociación de Profesores de Derecho internacional $y$ relaciones internacionales. Problemas internacionales del medio ambiente, Barcelona, Universidad Autónoma de Barcelona, pp. 55-94.

Brañes, Raúl, 1995: La responsabilidad por el daño ambiental, Panamá: PNUMA.

Castro Valle, Claudia María, 2014: "Soluciones del Derecho Internacional privado para deducir responsabilidad civil por daño ambiental transfronterizo en Honduras”, Innovare, Revista de Ciencia y Tecnología, Vol. 3, No 1, pp. 1-13.

Drnas De Clément, Zlata, 2012: "Principio de soberanía estatal en el acuerdo sobre el acuífero y en el proyecto de la CDI sobre los acuíferos transfronterizos”. RECORDIP, Vol. 1, N 1 . 
Elorrio, Magdalena Gracia, 2011: “Una aproximación al estándar de debida diligencia de los Estados partes en la gestión del sistema acuifero guaraní”. RECORDIP, Vol. 1, No 2 .

GARCía CASTREJón, Jemina, 2006: "Panorama de la responsabilidad internacional por daño ambiental”, en Carmona Lara, María del Carmen y Hernández Meza, Lourdes (Coordinadoras). Temas selectos de Derecho ambiental. México, Instituto de investigaciones jurídicas de la UNAM, pp. 467-508.

Gomis Catalá, Lucía, 1998: Responsabilidad por daños al medioambiente, Pamplona: Aranzadi.

KREUZER, Karl, 1992: "Environmental disturbance and damage in the context of private international law", Revista española de derecho internacional, Vol. 44, No 1 .

Martín Mateo, Ramón, 2000: “Avances en la efectividad de la responsabilidad ambiental”, en Moreno Martínez, Juan Antonio (Coordinador). Perfiles de la responsabilidad civil en el nuevo milenio, Madrid, Dykinson, pp. 322-331.

NafZiger, James A. R., 2002: “Avoiding courtroom "conflicts” whenever possible”, en Nafziger, James A. R. y Symeonides, Symeon C. (Editores). Law and justice in a multistate world. Essays in honor of Arthur T. von Mehren. Ardsley, Transnational Publishers, pp. 341-352.

OrganiZaCión de las Naciones Unidas, 2017: "Status as at: 20-09-2017 05:00:37 EDT, Chapter XXI, Law of the Sea”. Disponible en HTTPS://TREATIES.UN.ORG/PAGES/VIEWDETAILSIII. ASPX?SRC=TREATY\&MTDSG_NO=XXI-6\&CHAPTER=21\&TEMP=MTDSG3\&CLANG= EN\#ENDDEC. [Fecha de consulta: 20.09.2017].

Ortiz Ahlf, Loretta, 1999: "Responsabilidad por Daños Transfronterizos", Jurídica, Anuario del Departamento de Derecho de la Universidad Iberoamericana, México, Universidad Iberoamericana, $\mathrm{N}^{\circ} 29$.

Palao Moreno, Guillermo, 1998: La responsabilidad civil por daños al medioambiente. Valencia: Tirant Lo Blanch.

Palao Moreno, Guillermo, 2016: "Lección 20a , Obligaciones Extracontractuales" en Esplugues C., Iglesias, J. y Palao G., Derecho Internacional Privado (10 a edición), Valencia, Tirant Lo Blanch, pp. 643-670.

Pastor Ridruejo, José, 2015: Curso de Derecho internacional Público y de Organizaciones Internacionales (19 edición), Madrid: Tecnos.

Percival, Robert, 2010: "Liability for Global Environmental Harm and the Evolving Relationship between Public and Private Law", Maryland Journal of International Law, Vol. 10, No 1.

Zilioli, Chiara, 1995: Il risarcimento del danno derivante da incidente industriali transnazionali, Milán: Giuffrè.

Normas citadas

Acuerdo Regional sobre el Movimiento Transfronterizo de Desechos Peligrosos, adoptado el 11 de diciembre de 1992, publicado en Honduras el 28 de agosto de 1993.

Convención de las Naciones Unidas sobre el Derecho del Mar, adoptada el 30 de abril de 1982, publicada en Honduras el 27 de septiembre de 1993.

Convención Interamericana sobre Competencia en la Esfera Internacional para la Eficacia Extraterritorial de las Sentencias Extranjeras, adoptada el 24 de mayo de 1984.

Convención Interamericana sobre el Cumplimiento de Medidas Cautelares, adoptada el 5 de agosto de 1978.

Convención Interamericana sobre Exhortos o Cartas Rogatorias, adoptada el 30 de enero de 1975, publicada en H9onduras el 1 de junio de 1978.

Convención Interamericana sobre la Recepción de Pruebas en el Extranjero, adoptada el 30 de enero de 1975, publicada en Honduras el 5 de junio de 1978. 
Convención Interamericana sobre Normas Generales de Derecho Internacional Privado, adoptada el 5 de agosto de 1979, publicada en Honduras el 6 de junio de 1930.

Convención Internacional sobre Responsabilidad Civil por Daños debidos a la Contaminación por Hidrocarburos, adoptado el 29 de noviembre de 1969, publicada en Honduras con fecha 21 de junio de 1997.

Convención sobre Derecho Internacional Privado, adoptada el 20 de febrero de 1928.

Convención sobre la responsabilidad de los explotadores de buques nucleares, adoptada el 25 de mayo de 1962.

Convención sobre responsabilidad civil por daños nucleares, adoptada el 21 de mayo de 1963.

Convención sobre Responsabilidad de Terceros en el Sector de la Energía Nuclear, adoptada el 29 de julio de 1960.

Convenio del Consejo de Europa sobre la responsabilidad civil por los daños derivados de actividades peligrosas para el medio ambiente, adoptada el 21 de julio de 1993.

Convenio de Bruselas relativo a la responsabilidad civil en la esfera del transporte marítimo de sustancias nucleares, adoptado el 17 de diciembre de 1971.

Convenio Internacional de Indemnización de Daños causados por la Contaminación de Hidrocarburos, adoptado el 18 de diciembre de 1971.

Convenio sobre Diversidad Biológica, adoptada el 5 de junio de 1992, publicada en Honduras el 10 de junio de 1995 .

Convenio sobre el control de los movimientos transfronterizos de los residuos peligrosos y su eliminación, adoptado el 22 de marzo de 1989, publicado en Honduras el 28 de octubre de 1995.

Declaración sobre Medio Ambiente Humano y Desarrollo, adoptada el 16 de junio de 1972

Declaración sobre el Medio Ambiente Humano y el Desarrollo, adoptada el 14 de junio de 1992.

Protocolo Adicional a la Convención sobre Responsabilidad de Terceros en el Sector de la Energía Nuclear, adoptado el 28 de enero de 1964.

Protocolo sobre Seguridad en la Biotecnología, adoptado el 29 de enero de 2000, publicado en Honduras el 7 de octubre de 2008.

Protocolo sobre responsabilidad y compensación suplementario al protocolo de Cartagena sobre seguridad de la biotecnología, adoptado el 15 de octubre de 2010.

\section{Jurisprudencia citada}

CorTe Internacional de Justicia, 9 de abril de 1949, Recueil 1949, p. 4.

CoRTe Internacional de Justicia, 25 de septiembre de 1997, Recueil 1997, p. 7.

Corte Internacional de Justicia, 20 de abril de 2010, Recueil 2010, p. 4.

ConTe Suprema de Justicia de Honduras, 19 de octubre de 2006, No SJCSJ-RI0066.

Tribunal Permanente de Arbitraje, 4 de abril de 1928, Recueil Vol. II, pp. 829-871.

Tribunal Permanente de Arbitraje, 16 de abril de 1938 y 11 de marzo de 1941, Recueil Vol. III, pp. 1905-1982.

Tribunal Permanente de Arbitraje, 16 de noviembre de 1957, Recueil Vol. XII, pp. 281-317. 